\title{
How the Ombudsman Provides Leadership to the Public Sector Enterprises
}

\author{
Colin Neave \\ Commonwealth Ombudsman, Australia
}

\section{Introduction}

I would like to acknowledge the traditional owners of the land on which we meet, and pay my respects to their elders, both past and present.

I propose to talk, along with Annwyn Godwin, the Merit Protection Commissioner, about how strong leadership works hand-in-hand with good governance.

Annwyn and I felt it was appropriate, given our respective roles and experiences, to jointly address the topic from a public sector point of view.

We hope our presentation gives you an insight into how our two organisations are emphasising the importance of leadership within the Australian Public Service, in order to promote good governance in that Service.

There are many synergies between Annwyn's organisation and mine.

Annwyn will elaborate on her role during her presentation, but essentially she and her staff provide assurance, in key areas of the Australian Public Service employment framework, that the APS Values and employment principles are being applied effectively by agencies.

These key areas are a fair system of review of employment decisions and actions, ethical standards, and merit-based employment decisions.

The Merit Protection Commissioner may also conduct an investigation into whether an APS employee has breached the APS Code of Conduct.

My office considers and investigates complaints from people who believe they have been treated unfairly or unreasonably by an Australian Government department or agency.

We also monitor the operations of law-enforcement agencies such as the Australian Federal Police, and manage the Public Interest Disclosure scheme, which in itself is part of an integrated approach to promoting ethical values in the Commonwealth public sector. So while we are both, in the simplest terms, complaints agencies, we also both have a strong focus on promoting ethical behaviour, accountability, fairness and integrity - and championing leadership.

Copyright $(0) 2015$ Victoria University. This document has been published as part of the Journal of Law and Governance in both online and print formats. Educational and non-profit institutions are granted a non-exclusive licence to utilise this document in whole or in part for personal or classroom use without fee, provided that correct attribution and citation are made and this copyright statement is reproduced. Any other usage is prohibited without the express permission of the publisher. 
During my part of the presentation I will cover four topics:

- The Ombudsman's role

- What is governance?

- How can agencies better utilise evidence or business intelligence to improve governance?

- What is effective leadership and why is it important for good governance?

\section{Ombudsman's role}

Ombudsman institutions have been established in Australia for, in some cases, more than 40 years. They handle complaints against every tier of government - state, territory and local - and against various service providers in the private sector.

This experience engenders an expertise in complaint handling and in assessing complaint-handling systems.

The notion is now embedded in Australia that people have a right to complain against government, without hindrance or reprisal, and to have their complaint resolved on its merits according to the applicable rules and the evidence.

The Commonwealth Ombudsman has no power to force an agency to change a decision or provide a service and must rely on agencies to cooperate to resolve problems. However, the majority of recommendations we make are accepted by agencies.

Industry ombudsmen have determinative powers.

As the Ombudsman I may choose to use my 'own motion' power to initiate an investigation. I will often exercise this power following receipt of several complaints about the same issue, indicating a recurring problem.

An own motion investigation can look comprehensively at the scale of a problem, the likely causes and possible remedial action, either specifically in an individual case, or generally by a change to legislation or administrative policies or procedures.

Own motion investigations that result in published reports have become increasingly important, with the uptake of recommendations producing measurable improvements to government administration and service delivery.

It is through reports (own motion and other reports) that ombudsmen, in effect, promote good governance, accountability and transparency. Through oversight of government administration and service delivery, we contribute to improving accountability and good governance in three main ways:

1. Resolving individual disputes. By investigating complaints from individuals, ombudsmen safeguard citizens against government interference with individual liberties and give them a voice to complain where they would otherwise fear to do so. ${ }^{1}$ Ombudsmen are often the only avenue readily available to individual citizens seeking recourse on matters of maladministration or official misconduct that affect their everyday lives. Because ombudsman services are free, they are particularly valuable to poor, marginalised and vulnerable people.

2. Investigating systemic problems. We have the power to investigate broad issues on our own initiative. Problems that may affect many members of the public can be fixed through an ombudsman investigation, followed by publicity for the findings, reporting to the Parliament and subsequent implementation of the recommendations.

\footnotetext{
${ }^{1}$ John Walters, The role of the Ombudsman in promoting and protecting human rights - should it become a national human rights institution?', Speech delivered at the 2012 IOI World Conference
} 
3. Improving public sector performance. This works in two ways: directly, where the information from complaints about areas of poor service delivery is fed back to agencies from the ombudsman; and indirectly, where the potential oversight of each decision by the ombudsman is an incentive for public servants to improve the quality of their actions and decisions.

We can add a fourth element: monitoring law enforcement agencies for their compliance with the relevant legislation.

That then is a brief overview of what my office does.

\section{What is governance?}

Many have worked on defining governance.

In researching this presentation I was intrigued by what Canada's Institute on Governance has to say about it. The institute says that most definitions of governance rest on three dimensions:

- authority

- decision making

- accountability.

Each of those characteristics, you will note, applies equally to a public and a private sector organisation or venture.

Another definition that struck me was the GoodGovernance.org site from Victoria. It states that:

"Good governance is about the processes for making and implementing decisions. It's not about making 'correct' decisions, but about the best possible process for making those decisions.

Note the point they make that it's not necessarily about making the correct decision, but about having the best possible process in place for making it, which is a critical point for a government agency.

The website goes on to say that the characteristics of good governance are:

- accountability

- transparency

- responsiveness

- equitability and inclusiveness

- effectiveness and efficiency

- it follows the rule of law

- it is participatory.

So governance is actually a series of mechanisms, but none of those mechanisms matter without effective and engaged leadership.

So the logical next question is, what is good leadership?

It's a topic in which I have a particular interest in and have been talking about in various fora over the past few years, especially since I became Commonwealth Ombudsman.

That's because, in my experience, organisations that are well led have fewer complaints, or handle complaints well.

Leadership is a concept that is difficult to define and even more difficult to measure. 
In the simplest terms, it is generally regarded as influencing others - formally or informally - to accomplish a task. It provides direction, encouragement and inspiration to motivate a team to achieve organisational success.

Most of us in the public sector don't get to spend much of our working life focusing on leadership. In fact we will often be promoted or appointed to a leadership role based on our subject matter knowledge.

Generally we are specialists - lawyers, HR people, policy experts and so on - who rise to positions of responsibility and leadership, often without much specific instruction in leadership.

But as agency heads or CEOs or managers, it is a very important aspect of our roles.

Poor governance can lead to agencies encountering an increasing number of cases of fraud and corruption.

Good leadership, as I will explain further in a moment, promotes better administration, which in turn makes agencies more resistant to corruption.

\section{How can agencies better utilise evidence or business intelligence to improve governance?}

It has been said many times in my office - complaints from members of the public are a strategic resource.

One way in which agencies can take advantage of this free resource is to shift their attitude towards complaints.

That means making it easy for people to make complaints and ensuring that complaint-handling processes are not only set up to effectively resolve issues for individuals, but to help identify systemic administrative problems as, or ideally before, they arise.

It is worth asking, why have a complaints system? I suppose there are at least two answers to that.

The first is, for efficiency's sake. A complaints system provides a framework for dealing with complaints and contributes to continuous improvement. It can help preserve working relationships with individuals, and, often, it helps prevent disputes escalating into major problems for an agency.

The second reason is, quite simply, because we have a moral imperative to do so. The community has a right to use government services and a right to complain if those services are poor or inadequate.

The consequences of failing to deal with complaints is confirmed by consumer research showing that it is more profitable for a business to keep and deal with its dissatisfied customers, than to have them take their dissatisfaction elsewhere.

This lesson applies equally to government agencies, where dealing with a complaint in a professional and courteous manner at the outset can prevent prolonged, entrenched correspondence with the complainant later on.

Drawing attention to system problems at an early stage can avert costly and damaging mistakes and disputes.

There are further interesting facts about unhappy customers. Again these statistics are mainly relevant to commercial enterprises, but they apply equally I think to the public's interaction with government organisations. 
Research shows that:

- for every customer complaint there are 26 other unhappy customers who haven't complained. So the actual complaint is just the tip of the iceberg

- 96 per cent of unhappy customers don't complain, but 91 per cent of those will simply leave and never come back

- a dissatisfied customer will tell between nine and 15 people about their experience - the power of word of mouth

- a customer is four times more likely to defect to a competitor if the problem is service-related than price-or product-related. An important point to note: it seems service is more important than price or range

- it costs six to seven times more to acquire a new customer than retain an existing one.

However, on the reverse side, research shows that customers who get their issue satisfactorily resolved tell four to six people about their experience, and dissatisfied customers whose complaints are taken care of are more likely to remain loyal satisfied customers.

The point is, we all make mistakes. Errors, misunderstandings, client dissatisfaction and unexpected problems happen in all administrative systems.

It is how we manage those mistakes that defines us as an organisation and determines if we will continue to have "return business".

It is fair to say that up to about 20 years ago, most APS departments and agencies looked upon complaints as a nuisance.

I am pleased to say things have changed substantially. Agencies now accept that complaints are a predictable and necessary part of business, and are taking the issue more seriously.

Most Australian Government agencies now have well-developed complaint-handling systems in place, and they treat complaints as a valuable source of information for continuous business improvement.

And that makes good sense. Agencies should embrace feedback, whether it's from the public, its minister or an organisation like mine.

\section{What is effective leadership and why is it important for good governance?}

As I mentioned earlier, I have been prompted to contemplate the topic of leadership because, over the past two or so years in my organisation, it has become clear that we needed to work, ourselves, on 'leadership'.

This is not surprising given the structural changes we have undergone over time and the long periods during which senior positions were filled temporarily. This state of affairs is common in the public sector at present.

So I have given a lot of thought to the issue and have come up with what I consider to be the essential features of good leadership in a public administration organisation such as mine.

It seems to me there is no single, magic leadership quality, but rather a collection of attributes. I will step you through my top 10.

First and foremost is a commitment to openness, perhaps not surprising in an integrity role such as ours, but not always easy in practice. 
To be as fully informed as possible about the challenges being faced as an ombudsman, and to be frank and open about what an office might be engaged in as a result, is critical. There is a need to share information about those challenges with staff.

Implicit in the word openness is the concept of honesty. The term being 'frank and open' comes to mind.

It is a principle with which I do my best to comply and, indeed, we all should be frank and open with each other: leaders with staff and staff with each other, and leaders with other leaders, whether in government or private sector organisations.

All the easier, then, to be decisive - to make decisions in full knowledge of all the relevant facts and with the benefit of full and frank discussion. That does not lead to quick decisions, but it does mean being prepared to make a call.

Leaders are also courageous. This, of course, does not mean making foolhardy decisions but, rather, decisions are made in circumstances where the phrase 'damned if you do and damned if you don' $t$ ' is relevant.

Courage to accept risk is an attribute of a good leader. Decision-making courage is demonstrated where a decision is made which is likely to be unpopular, but, on balance, and factoring in all the possibilities and permutations, that decision is for the best.

Leaders accept responsibility. When public criticism is the result of a decision, we take responsibility for it even though it might have been made on the advice of someone reporting to us.

And of course, when a decision is made which leads to praise being handed out, it is most important that we share the glory for an excellent result with those who have contributed. Very few good results (if any) occur as a result of the actions of one person.

Good leaders also communicate clearly, mindful that what they say minimises the risk of misunderstandings.

And, most importantly, good leaders clearly state what they think the general direction is, providing an essential framework for all those who work with them to operate effectively.

Flexibility is important, and consistency.

Sometimes it is necessary to make a very quick decision which turns out to be wrong in the circumstances. Good leaders correct the decision as soon as they can and do not feel bound by a decision which clearly has an adverse result as far as the organisation is concerned.

Good leaders are also genuinely interested in the affairs of the people with whom they work.

All of us in life face challenges at home as well as at work, and a leader who inspires loyalty and commitment in staff, will demonstrate empathy for an employee who might for any number of reasons be experiencing difficulties.

This is part of the fabric of values within any organisation, but perhaps even more so in an organisation like mine that stakes its reputation and authority on its own actions.

Leaders also demonstrate a degree of selflessness. What does that mean?

Where an organisation has a clear set of objectives within a published and agreed strategic framework of which those objectives are part, then any deviation from that strategic framework would be seen as a 'sometimes' commitment to an organisation. 
That deviation from the overall direction of the organisation is not the characteristic of a good leader.

So the personal interests of a leader must not adversely affect the way in which an organisation performs its role. Any personal interest must always be subsidiary to the direction of the organisation.

You may ask, then, how do those attributes flow through the APS? How does my office exhibit leadership within the APS?

Well, my office has shifted its focus to working more with departments and agencies - to influence them to treat people fairly through our investigations of their administration.

This approach makes much more sense in the current environment than a traditional positional approach. That is, we now look at issues systemically rather than as individual problems, in the vast majority of the cases with which we are involved.

It is an approach that allows us to demonstrate more of a leadership role in public administration.

We have made greater use of own motion investigations as a means of encouraging agencies to tackle the underlying causes of administrative problems.

We also now spend much more time analysing complaint trends to identify emerging issues, helping agencies to develop prevention strategies at an early stage.

And, importantly, we try wherever possible to highlight lessons learned from individual cases through the use of better practice guides, cases studies and recommendations that can be applied in different settings - including for ourselves.

Although a large part of our work will always be assessing and investigating individual complaints, I believe our future relevance depends on our ability to intelligently use the information gained through that work to build the capacity of agencies to effectively manage complaints themselves.

\section{Conclusion}

To conclude, there is no doubt that one of the biggest challenges facing the APS at the moment is leading people through a difficult and extended period of change.

It is times like these that true leaders step up and shine.

But we need to be conscious that leadership is more than managing and it's much more than just ensuring we comply with rules and regulations and frameworks. Good leadership is about providing a working environment that encourages and makes it safe for people to report acts of fraud and corruption. It is also about engendering a culture that resists corruption, and instead promotes ethical behaviour, accountability, fairness and integrity, thus enhancing governance.

Thank you for your time and attention. 
